\title{
Some Current Insights into Oxidative Stress
}

\section{Z. ĎURAČKOVÁ ${ }^{1}$}

${ }^{1}$ Institute of Medical Chemistry, Biochemistry and Clinical Biochemistry, Faculty of Medicine, Comenius University, Bratislava, Slovakia

Received July 2, 2009

Accepted November 12, 2009

On-line November 20, 2009

\section{Summary}

Oxidative stress is a phenomenon associated with pathogenetic mechanisms of several diseases including atherosclerosis, neurodegenerative diseases, such as Alzheimer's and Parkinson's disease, cancer, diabetes mellitus, inflammatory diseases, as well as psychological diseases or aging processes. Oxidative stress is defined as an imbalance between production of free radicals and reactive metabolites, so-called oxidants, and their elimination by protective mechanisms, referred to as antioxidative systems. This imbalance leads to damage of important biomolecules and organs with potential impact on the whole organism. Oxidative and antioxidative processes are associated with electron transfer influencing the redox state of cells and the organism. The changed redox state stimulates or inhibits activities of various signal proteins, resulting in a changed ability of signal pathways to influence the fate of cells. At present, the opinion that oxidative stress is not always harmful, has been accepted. Depending on the type of oxidants, intensity and time of redox imbalance as well as on the type of cells, oxidative stress can play a role in the regulation of other important processes through modulation of signal pathways, influencing synthesis of antioxidant enzymes, repair processes, inflammation, apoptosis and cell proliferation, and thus processes of malignity. Imprudent administration of antioxidants may therefore have a negative impact on the organism.

\section{Key words}

Reactive metabolites • Antioxidants • Oxidative stress • Redox stress • Signaling

\section{Corresponding author}

Z. Ďuračková, Institute of Medical Chemistry, Biochemistry and Clinical Biochemistry, Faculty of Medicine, Comenius University, Sasinkova 2, 81372 Bratislava, Slovakia. E-mail: zdenka.durackova@fmed.uniba.sk
Oxidative stress (OS) is a phenomenon associated with the action of free radicals and reactive metabolites in the organism.

Free radicals participate in a large number of subsequent reactions (Fig. 1), in which other very reactive metabolites are formed. They are derived from basic radical molecules, such as superoxide anion radical, shortly superoxide $\mathrm{O}_{2}{ }^{-}$, or nitric oxide (nitroxide) $\mathrm{NO}^{\bullet}$ (hereafter NO). Newly formed metabolites have a great oxidative ability and they are often more reactive than their maternal molecules. Such metabolites include e.g. the most reactive hydroxyl radical, $\mathrm{HO}$, or non-radical molecules such as hydrogen peroxide, singlet oxygen, peroxynitrite or hypochlorous acid (Ďuračková 2008).

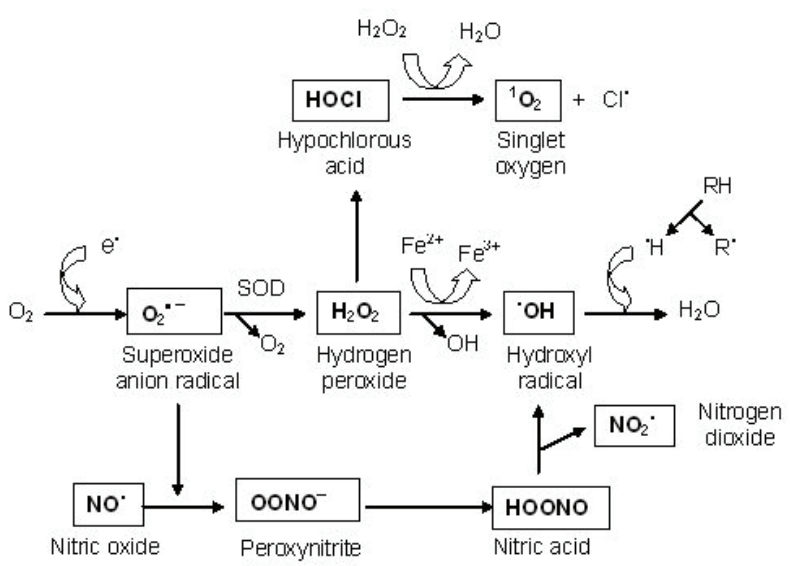

Fig. 1. Mutual association between free radicals and their reactive metabolites.

Interest in the biological significance of free radicals (FR) and their reactive metabolites (RM) (often 
named as reactive oxygen species, ROS) is dating back to the 80ties of the last century. Free radicals and RM have long been assumed to have only negative functions in the organism, especially when produced in large quantities, at the wrong site, in the presence of transition metal ions catalyzing radical reactions, and when protection of the organism against their toxic effect fails (Ďuračková et al. 1999).

Free radicals and RM have double functions. The positive function is associated e.g. with reproductive processes. Free radicals play an irreplaceable role in phagocytosis as one of the significant microbicidal systems, or in several biochemical reactions, e.g. hydroxylating, carboxylating or peroxidating reactions, or in the reduction of ribonucleotides. At present, FR and RM are assumed to have important biomodulating activities and a regulatory ability in signal transduction processes during transduction of intercellular information. Since under physiological conditions a certain level of FR and RM is required, complete suppression of FR formation would not be beneficial (Ďuračková et al. 1999).

To fight excessive production of FR and RM, the organism has built protective systems and mechanisms against their toxic effects. Protection of the organism is organized on three levels: (a) Systems preventing FR formation, such as inhibitors of enzymes catalyzing FR formation. Such enzymes include e.g. xanthine oxidase producing superoxide, which can be inhibited by allopurinol, or chelating agents trapping ions of transition metals and eliminating their catalytic activity during production of FR. (b) When these primary protective systems are insufficient and FR or RM have already been formed, scavengers and trappers of FR come into action and eliminate the high reactivity of FR by turning them into nonradical and nontoxic metabolites. These compounds are called antioxidants and they prevent oxidation of biologically important molecules by FR or RM. (c) If protection of the organism fails at this level, then repair systems recognize impaired molecules and decompose them, as it is in case of proteinases at oxidatively modified proteins, lipases at oxidatively damaged lipids, or DNA repair systems at modified DNA bases (Ďuračková 1998).

Both high-molecular-weight as well as lowmolecular-weight endogenous and exogenous compounds belong to antioxidants (Table 1). High-molecular-weight antioxidants include the enzymes superoxide dismutase, catalase and glutathione peroxidase and nonenzyme
Table 1. The most important endogenous and exogenous antioxidants.

Endogenous and exogenous antioxidants High molecular weight Low molecular weight

- Superoxide dismutase - Uric acid

- Glutathione peroxidase - Ascorbic acid

- Catalase

- Lipoic acid

- Albumin

- Glutathione

- Transferrin

- Tocopherol (vitamin E)

- Metallothioneins

- Flavonoids

antioxidants include proteins such as albumin, transportation protein for iron ions, transferrin and various metallothioneins. Low-molecular-weight antioxidants comprise hydrophilic as well as lipophilic compounds produced in the organism (endogenous antioxidants), e.g. uric acid, lipoic acid or glutathione and ubiquinol (reduced co-enzyme Q). The organism obtains exogenous antioxidants from food, e.g. vitamin C, vitamin E, and also compounds of polyphenolic structure synthesized in plants, including flavonoids (Ďuračková 2008).

The condition when the balance between production of FR and RM on the one hand and antioxidative protection of the organism on the other is disturbed and leads to damage of the organism, is generally denoted as oxidative stress (Štípek et al. 2000, Halliwell and Whiteman 2004). In spite of the fact that this term has been used commonly also in top professional journals, it is important to realize that it is not completely correct. Oxidation never proceeds alone, reduction must be its chemical partner. Therefore a more precise term for this phenomenon should be ,redox stress" (Ďuračková 2007).

The redox stress/oxidative stress is a very complicated and complex process (Fig. 2). Its impact on the organism depends on the type of oxidant, on the site and intensity of its production, on the composition and activities of various antioxidants, and on the ability of repair systems (汭uračková 2007).

Oxidative stress has been associated with several diseases, such as atherosclerosis and cardiovascular diseases (Racek et al. 1995, Pechán̆ et al. 2003, Ballinger 2005, Cherubini et al. 2005), neurodegenerative diseases 

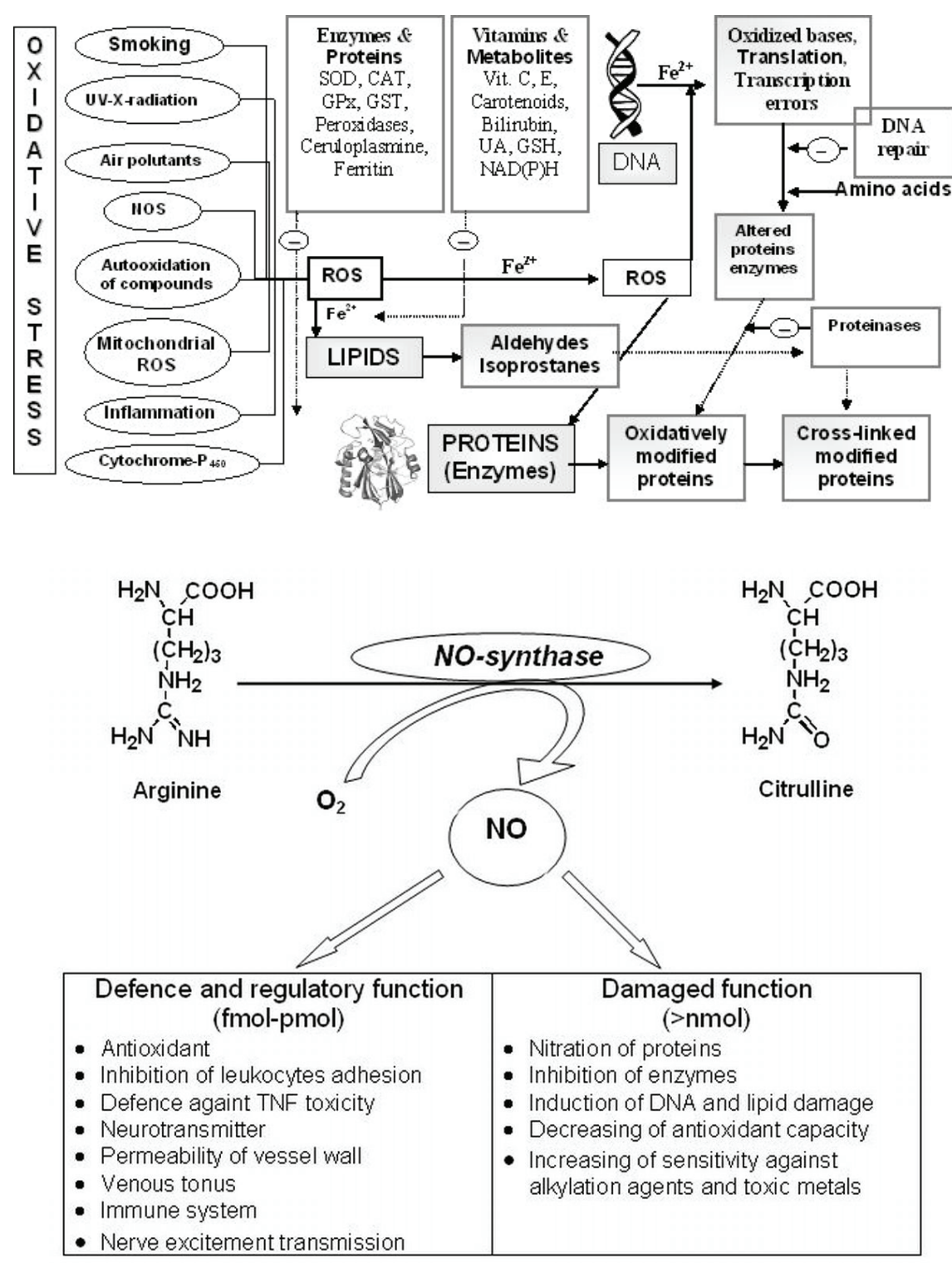

Fig. 2. Mutual association between oxidants and antioxidants.

NOS - NO-synthase

ROS - reactive oxygen species

CAT - catalase

SOD - superoxide dismutase

GPx - glutathione peroxidase

GST - glutathione S-transferase

UA - uric acid

GSH - glutathione reduced

Fig. 3. Nitric oxide and its participation in physiological and pathophysiological processes.

TNF - tumor necrosis factor
(Aruoma et al. 2007) such as Alzheimer's and Parkinson‘s diseases, diabetes mellitus (Muchová 1999, Muchová et al. 1999) and metabolic syndrome, skin and tumor diseases (Klaunig and Kamendulis 2004, Valko et al. 2006, Ghaffari 2008), but also psychic impairments such as schisophrenia or ADHD (attention deficit hyperactivity disease) (Chovanová et al. 2006, Trebatická et al. 2006, Dvořáková et al. 2007). Even physiological processes such as aging have been associated with the action of FR and RM and of antioxidants.

As mentioned above, under certain circumstances FR and RM are required for the proper function of some systems, but on the other hand, if they are produced in large quantities, they can become harmful to the organism. FR and RM can play a double role in the organism, a positive and a negative one.

A typical example of the double function of FR is a molecule of nitroxide. NO is formed from arginin by the action of NO-synthase (NOS) (Pryor et al. 2006). Nobody doubts the positive role of NO present at low concentrations (fmol) and produced by constitutive NOS, e.g. during vasodilating processes (eNOS) or during transmission of nerve impulses (nNOS). At higher concentrations (nmol), when NO is produced by catalytic action of inducible NOS (iNOS) (Fig. 3), NO can cause damage to proteins, lipids and DNA either directly or after reaction with superoxide, leading to the formation of the very reactive peroxynitrite anion (nitroperoxide)

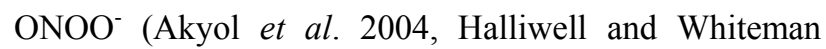
2004, Knott and Bossy-Wetzel 2009).

Similarly as NO, also other FR has double functions. For example superoxide or hydrogen peroxide at low concentrations exert positive effects on cell proliferation and survival through regulation of signal 


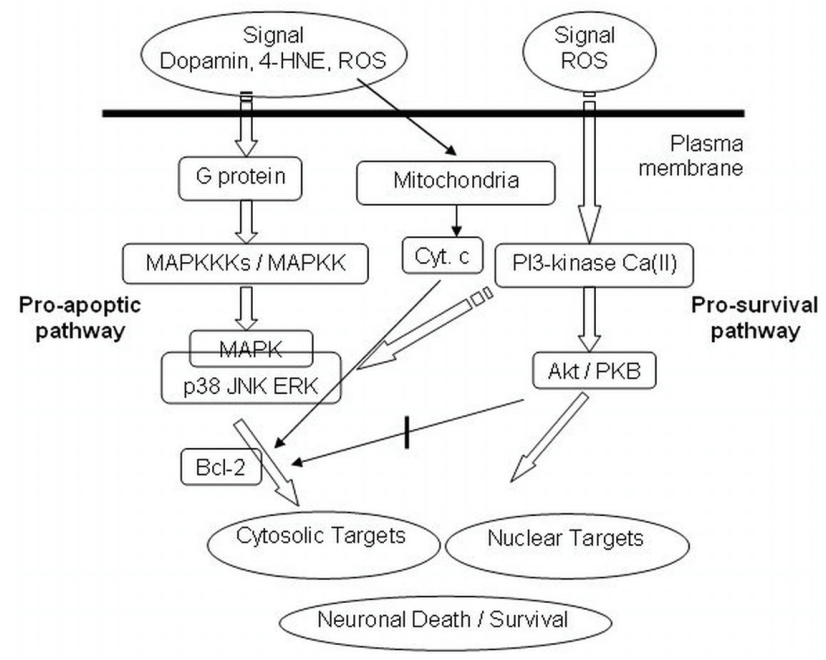

Fig. 4. Effect of oxidative stress on the "fate" of a nerve cell. ROS - reactive oxygen species, 4-HNE - 4-hydroxy-2-nonenale, MAPK - mitogene-activated protein kinase, MAPKK - kinase of MAPK, MAPKKK - kinase of MAPKK, p38 - mitogen-activated protein kinase responsive to stress stimuli, JNK - C-jun aminoterminal kinase, ERK - extracellular signal-related kinase, PI3 phosphatidylinositol 3-kinase, Akt/PKB - (protein kinase B) - type serin/threonine kinase, $\mathrm{Bcl}-2$ - apoptosis regulating protein, Cyt. c - cytochrome c.

transduction (Suzuki et al. 1997, Dröge 2002). At high concentrations, these compounds stimulate signal transduction pathways for cell apoptosis or necrosis. The questions to be addressed are: where is the border between the negative and the positive effect, what do these effects depend on, and how can we influence them.

Depending on the type and level of RM, time exposure, antioxidant status, activation of cellular repair systems, cells exposed to RM can respond differently increased proliferation, halted cell cycle, senescence, apoptosis or necrosis (Halliwell 2007). The response of cells to RM is dependent on the type of cells. For example, fibroblasts proliferate rapidly at RM levels that impair chondrocyte proliferation (Halliwell and Gutteridge 2007). The „fate“ of cells is dependent on the activities of different signal transduction pathways.

Increased oxidative stress has a negative effect on nerve cells. RM are redox active compounds and depending on their concentration they can exert either positive (cell proliferation) or negative effects (stop of cell growth, cell death) in nerve cells (Spencer 2005). Changes in redox state of cells lead to activation of proapoptotic signal proteins, especially through activation of MAPK kinase cascade and JNK protein (Fig. 4) (Spencer 2005, Ďuračková 2007).

On the other hand, survival of neurons is affected by modulation of signal transduction pathways through the main kinase of neuronal survival, i.e. serin/threonine kinase, which is an important effector of PI3-kinase (phosphatidyl-inositol 3-kinase). The kinase Akt inhibits the pro-apoptotic protein BAD from the family of apoptose regulating $\mathrm{Bcl}-2$ proteins and other pro-apoptotic members of the caspase family that specifically cleave poly(ADP-ribose)-polymerase, thus supporting cell survival.

Besides, RM can also influence the mitochondrial membrane (through its mitochondrial transition pore $\mathrm{mPT}$ ), resulting in the release of cytochrome c during apoptosis (Fig. 4).

Nerve cells require the stimulation of PI-3 kinase. It is a pivotal kinase in neural survival, while its inhibition could be one of the plausible pathways in the treatment of proliferative diseases.

In tumor cells communication via gap-junctions is decreased and this may facilitate their proliferation. This condition may be worsened at high level of RM (Klaunig and Kamendulis 2004). Another important tumor protein regulating ,fate" of cells is protein p53, described as „guardian of the genome“, which conserves stability by preventing genome mutation (Fig. 5). Its activity is intimately linked with cancer cells. On the basis of results reported by Bensaad and Vousden (2005), p53 is assumed to promote the transcription of genes encoding e.g. MnSOD, GPx as well as proteins regenerated oxidized peroxiredoxins (Fig. 5, (a) pathway). Furthermore, increased production of superoxide in cancer cells, for example after expression of ras oncogenes, is associated with increased activity of p53, which triggers senescence of cells. Higher p53 activity can cause production of RM by several mechanisms (for example through promotion of mitochondrial respiration with increased formation of RM), which may contribute to the cytostatic and proapoptotic effect (Fig. 5, (b) pathway). However, if RM are formed at a high level, they can inhibit p53 activity through oxidation of cysteine units in p53 protein (Fig. 5, (c) pathway). Formed RM cause accumulation of mutations and stimulation of tumorigenesis. Thus the relationship of $\mathrm{p} 53$ with $\mathrm{RM}$ is rather complex and intimate and it is very hard to say which way it will turn in a particular tumor cell (Halliwell 2007). However, depending on the type of cancer cells, also some other mechanisms related to RM activities are possible.

Similarly, different situations may occur in inflammatory cells, for example in chronic obstructive pulmonary disease (COPD) (Fig. 6). 

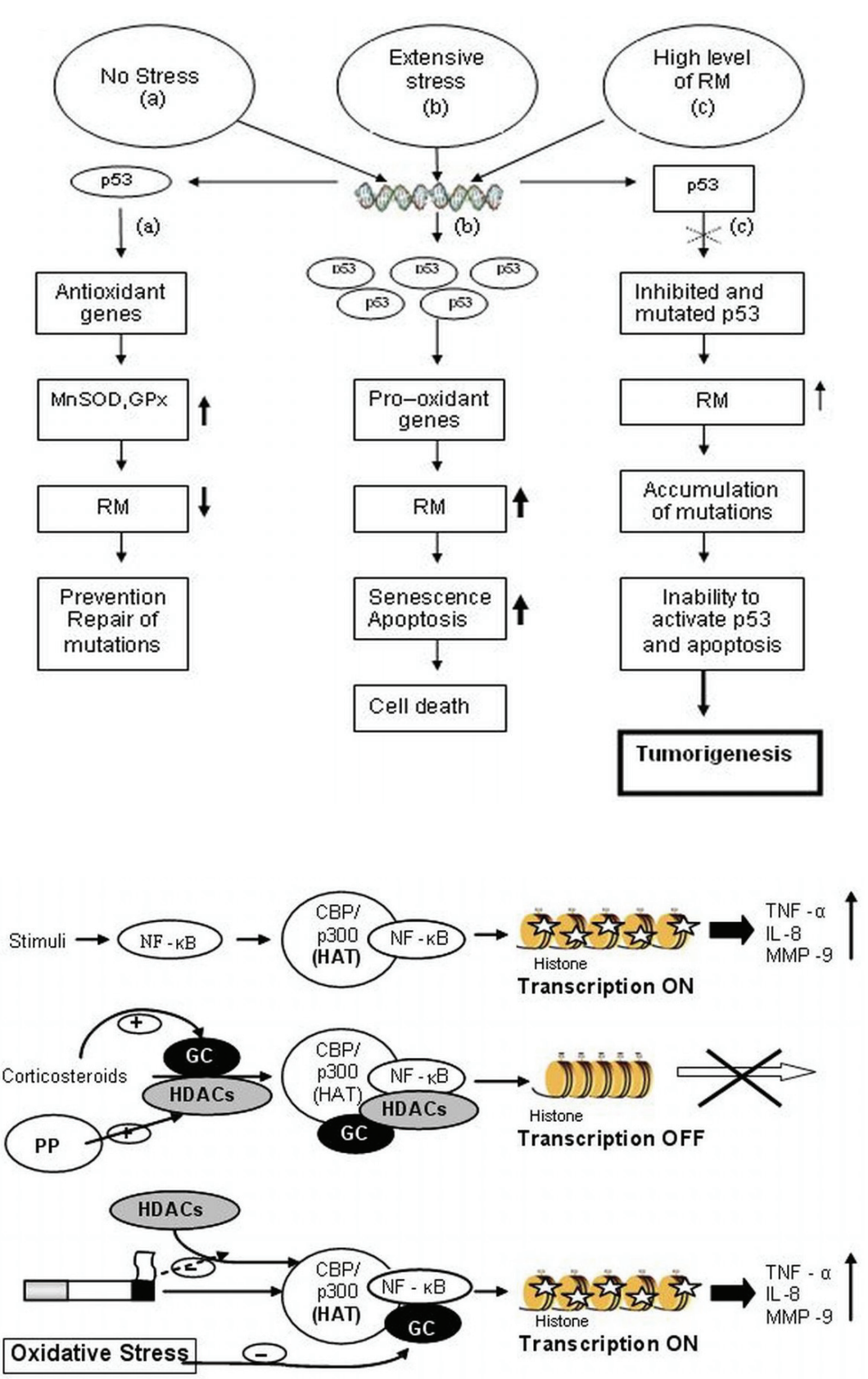

Fig. 5. Effect of oxidative stress on a tumor cell through tumor protein $\mathrm{p} 53$.

MnSOD - manganese superoxide dismutase

$\mathrm{GPx}$ - glutathione peroxidase

$\mathrm{RM}$ - reactive metabolite

p53 - tumor cytosol protein
Fig. 6. Oxidative stress and inflammatory cell. Modified according to Rahman et al. (2006) and Ďuračková (2007). HAT - histone acetyltransferase CBP/p300 - subunits of HAT HDAC - histone deacylase $\mathrm{GC}$ - glucocorticoid receptor TNF-a - tumor necrosis factor-alpha IL-8, MMP-9 - pro-inflammatory cytokines/ compounds $\mathrm{NF}-\mathrm{KB}$ - transcription factor $\mathrm{PP}$ - polyphenols
Pro-inflammatory cytokines and other stimuli activate transcription factor NF- $\mathrm{KB}$, they connect with coactivators - CBP (CREB Binding Protein) and p300 into an active acetyl transferase HAT (histone-acetyl transferase). By HAT catalysis histones become acetylated and DNA uncoils, DNA connects with polymerase and pro-inflammatory molecules become exprimated (Rahman et al. 2006).

During administration of anti-inflammatory corticoids, receptors for corticoids become activated, histone deacylase (HDAC) connects to the transcription complex, histones are deacylated and transcription is inhibited. In a millieu of oxidative stress, activities of both HDAC and the whole transcription complex are inhibited. In this situation, in spite of the presence of activated glucocorticoid receptor, acylation of histones and transcription of pro-inflammatory molecules begins, resulting in progression of inflammation.

Consequences of oxidative stress occur not only from the power of oxidative stress, from the type of cells affected by OS, but also from the period of redox imbalance. When OS acts for a short time, in spite of its strong intensity, the negative impact on a cell or organ need not be so harmful as during its long-term action. Long-term action of OS leads to a strong impairment of redox balance and yields damaged cells and organs. One example of such an action of OS is chronic inflammation.

The impact of oxidative stress on a cell does not 


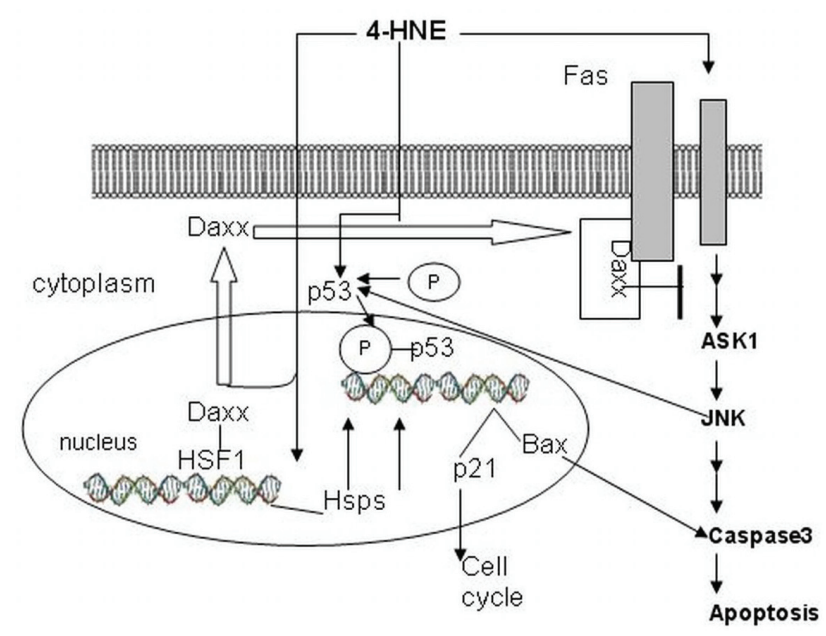

Fig. 7. Biomodulating activity of 4-hydroxy-2-nonenal. Modified according to Awasthi et al. (2008). 4-HNE - 4-hydroxy-2nonenal, Fas - receptor for TNF, ASK1 - apoptose signaling kinase, JNK - c-jun amino-terminal kinase, Daxx - transcription repressor, dead associated protein, p53 - cytosol protein, Bax pro-apoptotic gene, p21 - cell cycle arrest gene, HSF1 - heat shock factor, Hsps - heat shock proteins.

depend only on the above mentioned conditions (type of oxidants, intensity of OS, period of its action, type of cells with redox imbalance), but also on products formed during FR and RM action.

One of the products of oxidative damage to lipids is 4-hydroxy-2-nonenal (4-HNE). It is formed by oxidation of higher carboxylic acids (fatty acids), especially linolic and arachidonic acids. In spite of the fact that 4-HNE is a product of oxidative damage to fatty acids, regulatory properties in signal transduction pathways of cells have been ascribed to it recently (Fig. 7) (Awasthi et al. 2008).

4-HNE is a small diffusible molecule. It can interact with Fas receptor (receptor for TNF $\alpha$ - death receptor) on the cell membrane where it activates kinases ASK1 (apoptose signaling kinase) and JNK leading to activation of caspase and to apoptosis. However, 4-HNE can diffuse into a cell and interact with cytosol protein p53. After its phosphorylation, the protein is transported into the nucleus where it activates the expression of proapoptotic genes (Bax) and genes influencing the cell cycle (cell cycle arrest).

4-HNE then reacts with transcription repressor DAxx (death-associated protein) bound to HSF1 (heat shock factor). This complex leaves for the cytoplasm where it binds to Fas receptor and can inhibit activation of ASK1 (apoptosis signaling kinase), thus inhibiting apoptosis (Awasthi et al. 2008). Release of HSF1 from Daxx results in stimulation of heat shock proteins (Hsps) transcription (Fig. 7).

Further important products of fatty acid oxidation are isoprostanes. They are stereoisomers of prostaglandin $F$. Two types of isoprostanes have been defined. $\mathrm{F}_{2}$-isoprostanes are formed from arachidonic acid and $\mathrm{F}_{4}$-isoprostanes from eicosapentaenoic acid and docosahexaenoic acid. The latter are called neuroprostanes since they were isolated from nerve tissue. Increased levels of isoprostanes have been detected in several diseases, such as Alzheimer's disease, vascular diseases, diabetes mellitus, atherosclerosis, endothelial dysfunction, pulmonary diseases, and cardiobypasses (Basu 2006).

Arachidonic acid is a suitable substrate for oxidation. In the organism, arachidonic acid is oxidized by catalytic action of cyclooxygenase (COX) to eicosanoids, including prostaglandins, which are molecules with important regulatory function in immune and other processes. Prostaglandins have an important function in regulation of the inflammatory response. During nonenzymatic oxidation of arachidonic acid, stereoisomers of prostaglandins, called isoprostanes, are formed. Their representative is $\mathbf{8}$-iso- $\mathbf{P G F}_{2}$. This molecule is regarded to be an important marker of oxidative damage to lipids, despite the fact that the isoprostane levels are influenced also by the diet (they are present in food).

In experiments on rabbits, Basu (2006) found that $\mathrm{COX}$ was activated by endogenously produced isoprostanes during increased oxidation of arachidonic acid. The study found a similar regulatory activity also during exogenous i.v. administration of isoprostanes to rabbits, when COX activity was inhibited by the isoprostanes applied. These results induced an increased effort of scientists to study the biomodulating activity of isoprostanes (Fig. 8).

The mechanisms by which FR and oxidative stress can damage important biomolecules are not completely known, although many reactions, e.g. lipoperoxidation or oxidative damage to DNA, have already been elucidated to a certain extent. However, little is known about mechanisms by which FR and RM interfere with regulatory processes. It is assumed that they involve a direct interaction with signal molecules or structure and function changes brought on through their effect on the redox state, or some other as yet unknown mechanisms. 

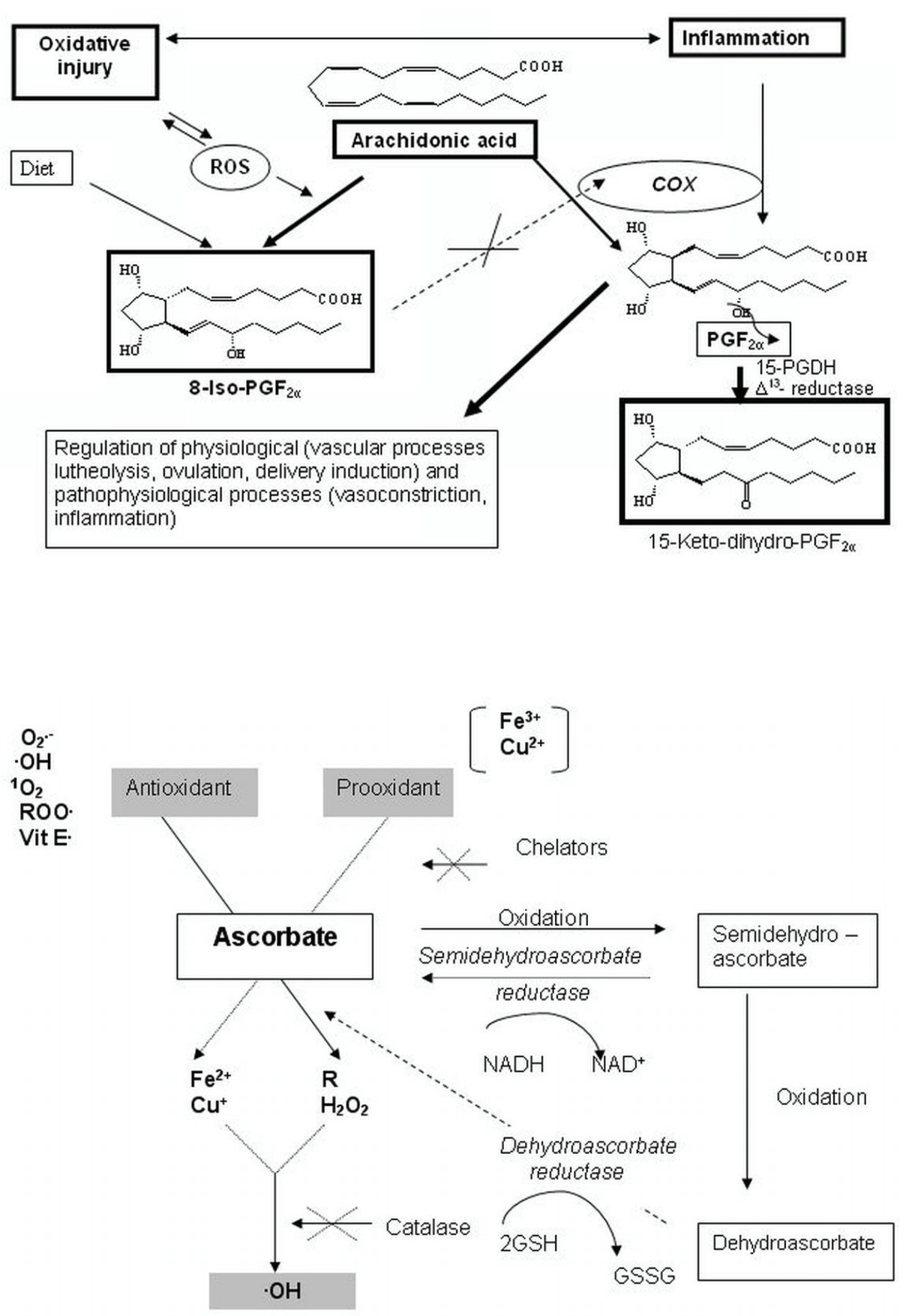

Fig. 8. Biomodulating activity of isoprostanes. Modified according to Basu (2006).

ROS - reactive oxygen species

COX - cyclooxygenase

PGF - prostaglandin

$15-\mathrm{PGDH}-\Delta^{13}$-reductase - NADHdependent 15-ketoprostaglandin delta13-reductase

Fig. 9. Ascorbic acid - antioxidant and potential prooxidant properties.
A regulatory function, positive or negative, is possesed not only by products of oxidative damage, but also by several antioxidants. A typical example is a hydrophilic antioxidant, ascorbic acid (vitamin C). A countless number of in vitro experiments but also many in vivo studies demonstrated an antioxidant function of ascorbate. Ascorbic acid can react with several FR producing semidehydro- or dehydroascorbic acids (DHA). DHA is then regenerated by enzymes present in the organism (semidehydroascorbic acid reductase and dehydroascorbic acid reductase) back to the functional ascorbate. However, if there are ions of transition metals around, ascorbic acid can reduce them and it itself becomes oxidized to DHA. Hydrogen peroxide formed in the reaction can then react with reduced metal ions leading to generation of hydroxyl radical. This reaction producing the dangerous hydroxyl radical is referred to as the Fenton type reaction (Fig. 9).

The opinion that this reaction is responsible for the toxicity of ascorbic acid in the presence of iron, copper or other heavy metal ions, has long been accepted. At present, however, this type of Fenton type reaction is 


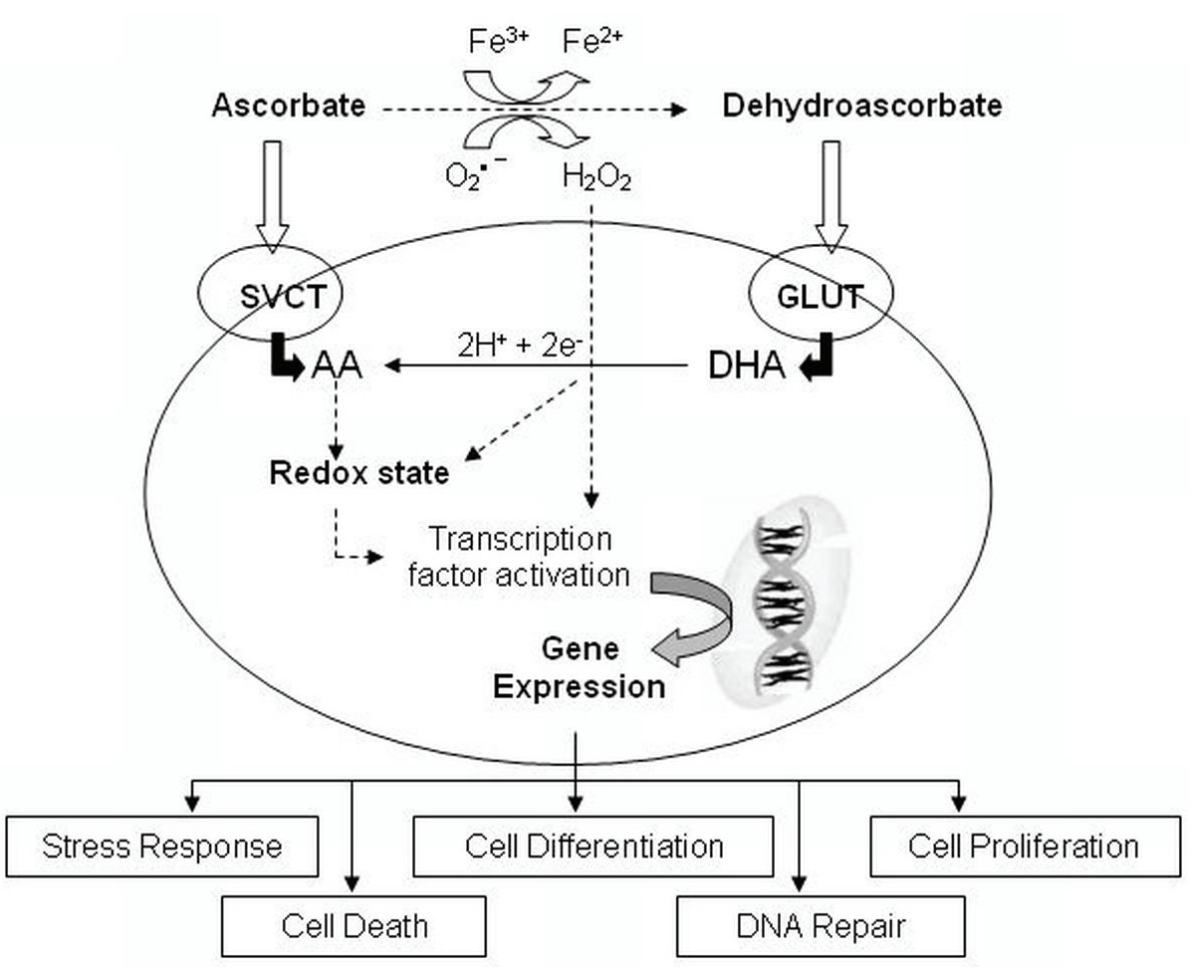

Fig. 10. Toxicity of ascorbic acid. Modified according to Duarte and Lunec (2005).

AA - ascorbic acid

DHA - dehydroascorbic acid

SVCT - Na-dependent transporter for $A A$

GLUT - glucose transporter not assumed to occur under in vivo conditions.

In the organism, the presence of iron is under strict control (with the exceptions associated with some iron overload diseases - hemochromatosis). Iron ions practically never occur in the free form (they are always bound to natural chelators), thus the Fenton type reaction in vivo is not likely to occur. There must be other mechanisms giving rise to toxicity of ascorbic acid.

Recently, some authors tended to support the opinion that toxicity of ascorbic acid (AA) was associated with its autooxidation. AA can be oxidized extracellulary in the presence of metal ions to dehydroascorbic acid, which is transported into the cell through the glucose transporter (GLUT), where it is reduced back to AA this movement of electrons changes the redox state of the cell influencing gene expression. AA is transported into the cell through the membrane by SVCT (Na-dependent transporter). Autooxidation of AA inside the cell can similarly change the redox state of the cell leading to modulation of gene expression (Fig. 10).

During autooxidation of AA, hydrogen peroxide is also produced, influencing the binding ability of redoxdependent transcription factors, resulting in activation of gene expression (dependent on the cell type), such as genes of stress proteins, apoptosis, differentiation and proliferation, or genes for DNA repair enzymes. Experiments with tissue cultures proved that derivatives of AA autooxidation (such as DHA) have a similar effect on cells as hydrogen peroxide. It has therefore been assumed that high concentrations of AA could have prooxidative effects through the change of redox balance in cells (Duarte and Lunec 2005).

Recently, Shin et al. (2004) have found that AA increases expression of genes different from those already known and required for differentiation of neurons. AA increases also the expression of genes for Fe-binding proteins and enzymes associated with OS (GPx, GST, metallothioneins). Gene expression is influenced through the redox effect. However, it is not known whether these mechanisms work also under in vivo conditions.

The above mentioned information suggests that not only FR and RM but also antioxidants can have double functions. Similarly as FR and RM, also antioxidants influence signal molecules through which they regulate the fate of cells.

Physical exercise affects the organism in a similar double-edged way. How is physical exercise associated with oxidative stress? It has long been assumed that during strenuous physical activity increased concentrations of FR and RM are generated. It was reasoned that increased consumption of oxygen during physical activity was leading to increased production of superoxide in mitochondria (Davies et al. 1982). Later on, Sastre et al. (1992) showed that mitochondria produced increased 


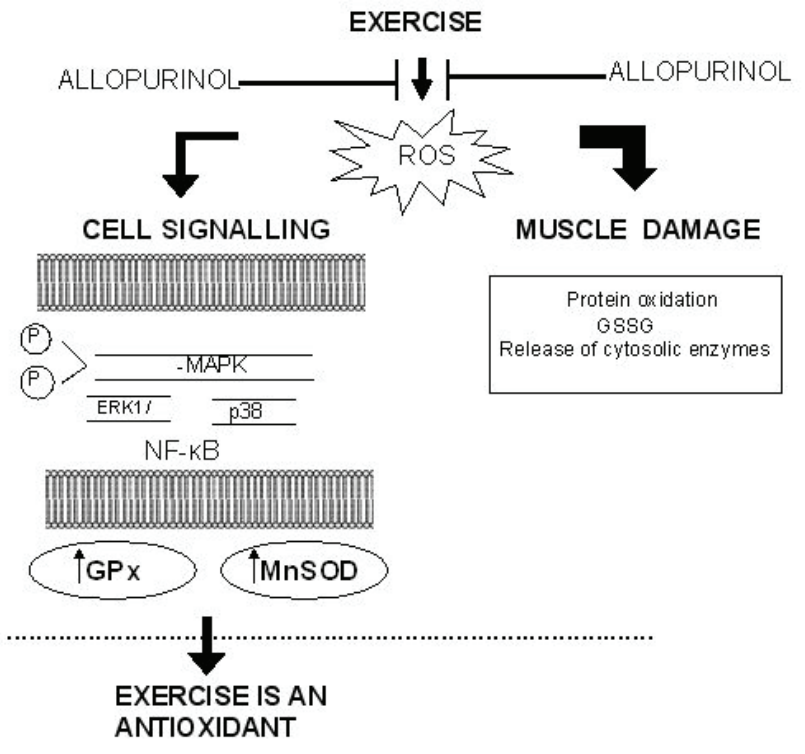

Fig. 11. Physical activity and oxidative stress. Modified according to Gomez-Cabrera et al. (2008). ROS - reactive oxygen species, MAPK - mitogene-activated protein kinase, ERK1 - extracellular signal-related kinase, p38 - mitogen-activated protein kinase responsive to stress stimuli, NF-KB - transcription factor, GPX glutathione peroxidase, MnSOD - manganese superoxide dismutase.

concentrations of superoxide only during very intensive exercise. Superoxide is produced in mitochondria in state 4 and 3. Superoxide formed in the respiratory chain represents only about $10 \%$ of all superoxide generated in muscle cells. Thus in addition to mitochondria, there must be also another source of superoxide production. Gómez-Cabrera et al. (2003) have shown that the alternative source of superoxide production in the muscle cell is a membrane xanthine oxidase (XO) (Reid et al. 1993, Pattwell et al. 2004). These authors confirmed their findings not only in animal experiments but also in cyclists participating in the Tour de France (Viña et al. 2006) who were taking the xanthine oxidase inhibitor allopurinol. Their superoxide production was inhibited.

Viña et al. (2006) also reported that the generated superoxide and its metabolites participating in oxidative stress exerted a concentration-dependent effect on muscle cells of sportsmen. Strong oxidative stress can cause damage to the muscle cells, while mild oxidative stress has a regulatory function during activation of antioxidant enzymes, and is thus involved in antioxidative protection. These authors found that mild physical activity increased NF- $\mathrm{KB}$ activity in the muscle of rats and thus also the gene expression for MnSOD and eNOS (Gómez-Cabrera et al. 2008) (Fig. 11).

Findings by Viña et al. (2006) were confirmed also by Reid et al. (1993) who pointed out that in

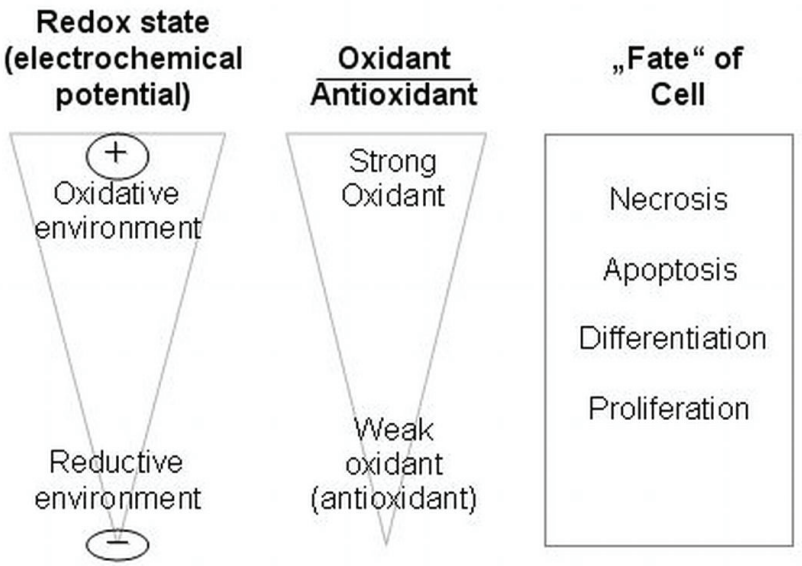

Fig. 12. Oxidative and reductive environment and "fate" of cell.

unfatigued skeletal muscle mild oxidative stress has a positive effect on excitation and muscle contraction.

Through the signal pathways, mild oxidative stress stimulates MAP-kinase pathways and further $\mathrm{NF}-\kappa \mathrm{B}$ with the following increase in the synthesis of antioxidant enzymes, protecting the muscle against oxidative damage. By contrast, strong oxidative stress can evoke oxidative damage to the muscle.

In conclusion, in sportsmen, mild oxidative stress is actually the antioxidant (Fig. 11).

Several studies in vitro but also in vivo confirmed these facts leading to reevaluation of the opinion on antioxidant supplementation during exercise and strenuous physical activity in sport races.

Antioxidants should not be taken before and during training exercise because they could intervene with muscle adaptation to the strenuous physical activity. Exercise stimulates higher synthesis of antioxidant enzymes. Antioxidant supplementation could inhibit the increased synthesis. However, during extreme activity in competition, increased levels and activities of antioxidants may not be sufficient, therefore administration of exogenous antioxidants just before and during the top sport performance could be appropriate.

At present, information on oxidative stress can be summarized as follows: generated FR, RM, some products of their action and also antioxidants significantly interfere with oxidation-reduction processes in cells and in the organism, changing the redox state of the cells. A changed redox state stimulates or inhibits activities of various signal proteins leading to a changed ability of signal pathways to influence the fate of cells. An oxidative milieu favors cell destruction by apoptosis or necrosis, and vice versa a reducing milieu favors cell survival (Fig. 12) (Ďuračková 2007). 
In conclusion, FR and RM are not „only bad“. Antioxidants are not „only good“. They both exert a regulatory function on many physiological and pathological processes, especially through modulation of the redox state of the organism. However, at present we do not know exactly where a border between their physiological and pathological effect is, what that effect depends on, and how a shift to one or to the other side can be influenced.

\section{Conflict of Interest}

There is no conflict of interest.

\section{Acknowledgements}

This work was supported by grants of the Ministry of Education of the SR 1/4310/07, 1/0224/08 and by Mind and Health, civil association. The author wishes to thank Dr. I. Žitňanová and Dr. M. Kouřilová for their assistance with the English, Ms. M. Saksová for her help with figures and Ms. L. Míková for her technical assistance with the literature.

\section{References}

AKYOL O, ZOROGLU SS, ARMUTCU F, SAHIN S, GUREL A: Nitric oxide as a physiopathological factor in neuropsychiatric disorders. In Vivo 18: 377-390, 2004.

ARUOMA OI, NEERGHEEN VS, BAHORUN T, JEN L-S: Free radicals, antioxidants and diabetes: embryopathy, retinopathy, neuropathy, nephropathy and cardiovascular complications. Neuroembryol Aging 4: 117-137, 2007.

AWASTHI YC, SHARMA R, SHARMA A, YADAV S, SINGHAL SS, CHAUDHARY P, AWASTHI S: Self-regulatory role of 4-hydroxynonenal in signaling for stress-induced programmed cell death. Free Radic Biol Med 45: 111$118,2008$.

BALLINGER SW: Mitochondrial dysfunction in cardiovascular disease. Free Radic Biol Med 38: 1278-1295, 2005.

BASU S: F2-isoprostane induced prostaglandin formation in the rabbit. Free Radic Res 40: 273-277, 2006.

BENSAAD K, VOUSDEN KH: Savior and slayer: the two faces of p53. Nat Med 11: 1306-1313, 2005.

CHERUBINI A, RUGGIERO C, POLIDORI MC, MECOCCI P: Potential markers of oxidative stress in stroke. Free Radic Biol Med 39: 841-852, 2005.

CHOVANOVÁ Z, MUCHOVÁ J, SIVOŇOVÁ M, DVOŘÁKOVÁ M, ŽITŇANOVÁ I, WACZULÍKOVÁ I, TREBATICKÁ J, ŠKODÁČEK I, ĎURAČKOVÁ Z: Effect of polyphenolic extract, Pycnogenol®, on the level of 8-oxoguanine in children suffering from attention deficit/hyperactivity disorder. Free Radic Res 40: 1003$1010,2006$.

DAVIES KJ, QUINTANILHA AT, BROOKS GA, PACKER L: Free radicals and tissue damage produced by exercise. Biochem Biophys Res Commun 107: 1198-1205, 1982.

DRÖGE W: Free radicals in the physiological control of cell function. Physiol Rev 82: 47-95, 2002.

DUARTE TL, LUNEC J: When is an antioxidant not an antioxidant? A review of novel actions and reactions of vitamin C. Free Radic Res 39: 671-686, 2005.

ĎURAČKOVÁ Z: Free Radicals and Antioxidants in Medicine (I) (in Slovak). SAP, Bratislava, 1998.

ĎURAČKOVÁ Z: Oxidants, antioxidants and oxidative stress. In: Mitochondrial Medicine. Mitochondrial Metabolism, Diseases, Diagnosis and Therapy. A GVOZDJÁKOVÁ (ed), Springer, Amsterdam, 2008, pp 19-49.

ĎURAČKOVÁ Z: Oxidants, antioxidants and redox stress. In: The Activity of Natural Compounds in Diseases Prevention and Therapy. Z ĎURAČKOVÁ, S KNASMÜLLER (eds), SAP, Bratislava, 2007, pp 11-59.

ĎURAČKOVÁ Z, BERGENDI L', ČÁRSKY J (eds): Free Radicals and Antioxidants in Medicine (II) (in Slovak). SAP, Bratislava, 1999.

DVOŘÁKOVÁ M, JEŽOVÁ D, BLAŽÍČEK P, TREBATICKÁ J, ŠKODÁČEK I, ŠUBA J, WACZULÍKOVÁ I, ROHDEWALD P, ĎURAČKOVÁ Z: Urinary catecholamines in children with attention deficit hyperactivity disorder (ADHD): modulation by a polyphenolic extract from pine bark (Pycnogenol $\left.{ }^{\circledR}\right)$. Nutr Neurosci 10: 151157, 2007.

GHAFFARI S: Oxidative stress in the regulation of normal and neoplastic hematopoiesis. Antioxid Redox Signal 10: 19231940, 2008. 
GÓMEZ-CABRERA MC, PALLARDÓ FV, SASTRE J, VIÑA J, GARCÍA-DEL-MORAL L: Allopurinol and markers of muscle damage among participants in the Tour de France. JAMA 289: 2503-2504, 2003.

GÓMEZ-CABRERA MC, DOMENECH E, VIÑA J: Moderate exercise is an antioxidant: upregulation of antioxidant genes by training. Free Radic Biol Med 44: 126-131, 2008.

HALLIWELL B: Oxidative stress and cancer: have we moved forward? Biochem J 401: 1-11, 2007.

HALLIWELL B, GUTTERIDGE JMC: Free Radicals in Biology and Medicine. 4th ed. Oxford University Press, Oxford, 2007.

HALLIWELL B, WHITEMAN M: Measuring reactive species and oxidative damage in vivo and in cell culture: how should you do it and what do the results mean? Br J Pharmacol 142: 231-255, 2004.

KLAUNIG JE, KAMENDULIS LM: The role of oxidative stress in carcinogenesis. Annu Rev Pharmacol Toxicol 44: 239267, 2004.

KNOTT AB, BOSSY-WETZEL E: Nitric oxide in health and disease of the nervous system. Antioxid Redox Signal 11: 541-553, 2009.

MUCHOVÁ J: Diabetes mellitus and antioxidans. In: Free Radicals and Antioxidants in Medicine (II) (in Slovak). Z ĎURAČKOVÁ, L' BERGENDI, J ČÁRSKY (eds), SAP, Bratislava, 1999, pp 203-232.

MUCHOVÁ J, LIPTÁKOVÁ A, ORSZÁGHOVÁ Z, GARAIOVÁ I, TISOŇ P, ČÁRSKY J, ĎURAČKOVÁ Z: Antioxidant systems in polymorphonuclear leukocytes of type 2 diabetes mellitus. Diabet Med 16: 74-78, 1999.

PATTWELL DM, MCARDLE A, MORGAN JE, PATRIDGE TA, JACKSON MJ: Release of reactive oxygen and nitrogen species from contracting skeletal muscle cells. Fre RadicBiol Med 37: 1064-1072, 2004.

PECHÁŇ I, DAŇOVÁ K, OLEJÁROVÁ I, HALČÁK L, RENDEKOVÁ V, FABIÁN J: Oxidative stress and antioxidant defense systems in patients after heart transplantation. Wien Klin Wochenschr 115: 648-651, 2003.

PRYOR WA, HOUK KN, FOOTE CS, FUKUTO JM, IGNARRO LJ, SQUADRITO GL, DAVIES KJ: Free radical biology and medicine: it's a gas, man! Am J Physiol 291: R491-R511, 2006.

RACEK J, TŘEŠKA V, KŘIŽAN V, HOLEČEK V, JEŘÁBEK Z: The significance of free radicals in operations of acute ischaemia of the limbs. (in Czech) Klin Biochem Metab 3: 103-105, 1995.

RAHMAN I, BISWAS SK, KIRKHAM PA: Regulation of inflammation and redox signaling by dietary polyphenols. Biochem Pharmacol 72: 1439-1452, 2006.

REID MB, KHAWLI FA, MOODY MR: Reactive oxygen in skeletal muscle. III. Contractility of unfatigued muscle. J Appl Physiol 75: 1081-1087, 1993.

SASTRE J, ASENSI M, GASCO E, PALLARDO FV, FERRERO JA, FURUKAWA T, VIÑA J: Exhaustive physical exercise causes oxidation of glutathione status in blood: prevention by antioxidant administration. Am J Physiol 263 (Pt 2): R992-R995, 1992.

SHIN DM, AHN JI, LEE KH, LEE YS, LEE YS: Ascorbic acid responsive genes during neuronal differentiation of embryonic stern cells. NeuroReport 15: 1959-1963, 2004.

SPENCER JPE: Interactions of flavonoids and their metabolites with cell signaling cascades. In: Nutrigenomics. G RIMBACH, J FUCHS, L PACKER (eds), Taylor \& Francis, Boca Raton, 2005, p 353-377.

ŠTÍPEK S, BOROVANSKÝ J, ČEJKOVÁ J, HOMOLKA J, KLENER P, LUKÁŠ M, ŠPIČÁK J, TESAŘ V, ZEMAN M, ZIMA T, ŽÁK A: Antioxidants and Free Radicals in Health and Disease (in Czech). Grada Publishing, Prague, 2000.

SUZUKI YJ, FORMAN HJ, SEVANIAN A: Oxidants as stimulators of signal transduction. Free Radic Biol Med 22: 269285, 1997.

TREBATICKÁ J, KOPASOVÁ S, HRADEČNÁ Z, ČINOVSKÝ K, ŠKODÁČEK I, ŠUBA J, MUCHOVÁ J, ŽITŇANOVÁ I, WACZULÍKOVÁ I, ROHDEWALD P, ĎURAČKOVÁ Z: Treatment of ADHD with French maritime pine bark extract Pycnogenol ${ }^{\circ}$. Eur Child Adolesc Psychiatry 15: 329-335, 2006.

VALKO M, RHODES CJ, MONCOL J, IZAKOVIC M, MAZUR M: Free radicals, metals and antioxidants in oxidative stress-induced cancer. Chem-Biol Interact 160: 1-40, 2006.

VIÑA J, BORRAS C, GOMEZ-CABRERA MC, ORR WC: Part of the series: from dietary antioxidants to regulators in cellular signalling and gene expression. Role of reactive oxygen species and (phyto)oestrogens in the modulation of adaptive response to stress. Free Radic Res 40: 111-119, 2006. 